\title{
Designing integrated interventions to improve nutrition and WASH behaviors in Kenya
}

Kimberly R. Jacob Arriola ${ }^{1 *}$ (D), Anna Ellis ${ }^{2}$, Amy Webb-Girard ${ }^{3}$, Emily Awino Ogutu², Emilie McClintic², Bethany Caruso $^{2}$ and Matthew C. Freeman ${ }^{2}$

\begin{abstract}
Background: Child stunting, an indicator of chronic malnutrition, is a global public health problem. Malnutrition during pregnancy and the first 2 years of life undermines the survival, growth, and development of children. Exposure to fecal pathogens vis-à-vis inadequate water, sanitation, and hygiene (WASH) has been implicated in the etiology of child stunting, highlighting the need to integrate WASH with nutrition-sensitive interventions to comprehensively address this complex problem. The aim of this study was to describe a systematic, theoretically informed approach (that drew from the Starr and Fornoff approach to the Theory of Change development and the Behavior Change Wheel approach) to design a multi-component and integrated social and behavior change intervention to improve WASH and nutrition-related behaviors in western Kenya.
\end{abstract}

Methods: This intervention was developed to be integrated into an existing project that utilized the care group model and aimed to create a culture of care and support for HIV/AIDS-affected children under two and their caregivers and was executed by local partners. We tested the newly created intervention packages in user-testing trials using an adapted Trials of Improved Practices approach to pilot acceptability and feasibility.

Results: Using authentic stakeholder engagement and relevant theories, we conducted an 8-step process: (1) conduct mixed methods formative research, (2) prioritize target behaviors, (3) use causal analysis to create problem trees, (4) develop solution trees and articulate assumptions and rationales for change, (5) link solution trees to intervention functions, (6) develop the intervention plan, (7) create the intervention packages, and (8) test and refine the intervention packages.

Conclusions: This study highlights the need to take a multi-sectorial, integrated approach that integrates contextually relevant behavior change theories with the experiential knowledge gleaned from stakeholders into the design of interventions that seek to reduce child stunting. This process resulted in the creation of intervention packages that grouped behaviors thematically to be most relevant and responsive to the population context. This work has the potential to make important contributions towards achievement of the United Nations' sustainable development goals.

Keywords: Water, sanitation, and hygiene, Malnutrition, Child stunting, Behavioral theory, Behavior change intervention, Maternal and child health

\footnotetext{
* Correspondence: kjacoba@emory.edu

${ }^{1}$ Department of Behavioral Sciences and Health Education, Rollins School of

Public Health, Emory University, Atlanta, GA, USA

Full list of author information is available at the end of the article
}

(c) The Author(s). 2020 Open Access This article is distributed under the terms of the Creative Commons Attribution 4.0 International License (http://creativecommons.org/licenses/by/4.0/), which permits unrestricted use, distribution, and reproduction in any medium, provided you give appropriate credit to the original author(s) and the source, provide a link to the Creative Commons license, and indicate if changes were made. The Creative Commons Public Domain Dedication waiver (http://creativecommons.org/publicdomain/zero/1.0/) applies to the data made available in this article, unless otherwise stated. 


\section{Background}

Child stunting, an indicator of chronic malnutrition, is a global public health problem. Malnutrition during pregnancy and the first 2 years of life undermines the survival, growth, and development of children [1,2]. The etiology of early childhood malnutrition is complex, involving interactions between parental feeding practices, dietary intakes, and nutrient absorptive capabilities. Gastrointestinal and other infectious diseases, determined by a household and community's access to adequate water, sanitation, hygiene, and health services, increase nutritional needs and can further exacerbate malnutrition [3-5]. If not addressed, malnutrition can impair gross motor, fine motor, and cognitive development with later implications for schooling success and economic productivity in adulthood. Chronic malnutrition in early childhood also predisposes individuals to cardiovascular disease in adulthood [3-5]. Global leaders recently pledged to reduce chronic malnutrition among children under age five by $40 \%$ by 2025 [6]. Nutrition-specific interventions-those aimed at improving nutrient intakes and diet practices-are, on their own, insufficient to achieve these reductions even when delivered at scale and with high coverage $[7,8]$. As a result, there is interest in developing, testing, and evaluating multi-sectorial and integrated approaches to tackle the underlying determinants of child nutrition $[9,10]$. Known as nutrition-sensitive approaches, these include nutritionsensitive agriculture [10,11], poverty reduction [9], girls' education [10, 12], birth spacing [13], and women's empowerment [14].

In addition, research implicates early and chronic, even asymptomatic, infections with fecal pathogens in the etiology of stunting $[15,16]$. Clean drinking water, sanitation facilities that hygienically separate feces from human contact, and appropriate hygiene behaviors, such as handwashing with soap-together known as WASHcan reduce exposures to harmful enteric pathogens of both human and animal origins [17]. In the absence of these environmental improvements and associated behaviors, children are at risk of stunting due to extended and repeated occurrences of diarrhea [18], soil-transmitted helminth infections [19], and asymptomatic infections that itself can lead to environmental enteric dysfunction, a chronic condition that reduces intestinal nutrient absorption $[20,21]$.

However, field trials have found limited efficacy and effectiveness of improving WASH on child growth [22-24]. While it may be that improvements to the hygienic environment do not impact stunting, it is more likely that they did not sufficiently reduce exposure to fecal pathogens because the interventions were not appropriate, were not delivered optimally, or did not sufficiently target the appropriate exposure pathways $[25,26]$.
One critical limitation of many studies assessing the impacts of WASH and nutrition interventions is that the approaches to change behavior are delivered in parallel, rather than as integrated packages. Menon and Frongillo [26], in their recent commentary, highlighted the need for integrated approaches that target the caregiving dyad's lived reality and the social (i.e., household and community members) and physical environment within which caregiving occurs. They recommended including or perhaps especially, integrating behavior change efforts seamlessly into daily routines. Moreover, the theoretical foundations of WASH and nutrition interventions are rarely described, and thus, the pathways explaining how interventions are expected to change behavior and ultimately reduce child stunting are poorly articulated [27-31]. Recent reviews highlight a need to provide sufficiently detailed descriptions of the process, theory, and evidence bases used to develop stunting reduction programs and their theories of change [29, 30, 32-34]. Such detail fosters transparency, allows for replication, and gives greater insights into what specific techniques work to change behavior and why.

\section{Theoretical and methodological foundations}

To that end, this study sought to develop an integrated WASH/nutrition behavior change intervention. To design the intervention, we applied two relevant theoretical and methodological frameworks: (1) the Starr and Fornoff [35] approach to Theory of change (TOC) development and (2) the Behavior Change Wheel (BCW) approach [36] to intervention design.

Theories of change are widely used in designing, planning, managing, evaluating, and scaling complex interventions [27, 34, 37, 38]. They are often developed through a backwards mapping approach that starts with a clear goal statement and then maps the required process of change to achieve that goal through delineation of antecedent outcomes, behaviors, and behavioral determinants [38]. This sequence of change is developed with a deep understanding of context, including the assumptions, motivations, worldviews, and philosophies of relevant stakeholders [38]. In addition to the sequence of change, TOCs articulate assumptions related to the reach, coverage, capacity change, program fidelity, behavior change, and benefits [39]. Such delineation permits a robust examination of the process of change. Experts recommend that a TOC should be developed as part of a multi-stakeholder and collaborative experiential learning exercise [40]. The Starr and Fornoff [35] process for TOC development entails engaging stakeholders to describe a current problem through formative research, map the underlying causes, identify the long-term changes needed to address the problem, and develop the activities that need to occur to create the desired long-term change. 
Given that a TOC is a pragmatic framework for describing how an intervention will produce change, it is strengthened by the integration of key behavioral, social, or psychological theories that explain why certain pathways to change are expected to exist [27, 28]. If integrated into a TOC properly, these theories explain the types of behavior change that are expected to occur and aid in specification of activities that may produce the desired behavior change. To that end, we adapted key steps from the $\mathrm{BCW}$ approach [36] to develop the intervention plan.

The BCW approach characterizes behavioral systems using the "COM-B" model. Analogous to that of Rothschild [41], the COM-B model hypothesizes that volitional behavior is determined by behavioral capability (or the physical and psychological skills necessary to perform the behavior), opportunity (or the physical and social supports or restraints on the behavior), and motivation (or the reflective and automatic processes that direct behavior). The $\mathrm{BCW}$ process, like the Starr and Fornoff approach to TOC development, begins with understanding and defining priority behaviors in a given context using formative research. Following specification of the behavior (i.e., the who, what, when, where, how often, and with whom) and using findings from formative research, the $\mathrm{BCW}$ approach applies the COM-B model to identify and characterize specific behaviors and behavioral antecedents known as theoretical domains [42]. These domains bridge to relevant behavior change approaches referred to as intervention functions [36, 42]. A taxonomy of behavior change techniques $[43,44]$ is then used to map intervention functions to specific and appropriate approaches that facilitate behavior change.

\section{Aims}

Aligned with a call to document intervention development processes, our manuscript describes a systematic and theoretically informed approach to design an integrated social and behavior change intervention to improve WASH and nutrition-related behaviors in western Kenya, with the goal of reducing child stunting [45]. Through application of the $\mathrm{BCW}$ to this work, we developed three thematic intervention packages to reduce child stunting: (1) food preparation and storage, (2) mealtime behaviors, and (3) clean family environment (see Table 1) [36]. Our approach balanced evidence from the peer-reviewed literature and stakeholder expertise. Our goals in presenting this detailed description of our intervention design process include fostering transparency, enabling replication, and providing greater insights into what specific techniques work to change behavior and why.

\section{Methods}

The integrated WASH/nutrition behavior change intervention was designed to be implemented as part of the
THRIVE II project executed by local partners of Catholic Relief Services, the primary implementing partner, in Kenya. THRIVE II was a two-year project that began in January 2016, of which the goal was to create a culture of care and support for HIV- and AIDS-affected children under 2 years and their caregivers in Kenya, Tanzania, and Malawi. It represented work that continued from the initial project, THRIVE, which had the same overall goal. The local partners, Homa Hills Community Development Organization and Mercy Orphans, were responsible for the supervision and ground support of the project. Using the Care Group model [46], THRIVE II provided ongoing support to caregivers of children under two years of age to practice early childhood stimulation, positive parenting, and optimal infant and young child feeding and WASH behaviors. Community health workers trained volunteer lead mothers who disseminate health messaging to small groups (6-12 mothers) and conduct home visits to support ongoing behavior change. At the community level, strategies were implemented to strengthen the capacity of health facilities to support early stimulation and positive parenting counseling. In Kenya, the project targeted an estimated population of 3120 pregnant mothers and caregivers of children below 2 years of age.

We tested the newly created intervention packages in user testing trials using an adapted Trials of improved practices (TIPs) approach [47]. User testing sought to give participants voice in program design and to gauge the acceptability and feasibility of the intervention components as a way to maximize uptake and effectiveness. The duration of TIPs varies depending on the behavior but often lasts 5-7 days for nutrition-related iterations. Trials of improved practice often occur over three visits, with the first visit used to assess challenges performing the optimal behaviors, the second visit to provide feedback and negotiate adoption of potential solutions, and a third visit to evaluate uptake and gather family perspectives on the solution. Analysis of both quantitative and qualitative data from these three visits serves to identify key determinants of and feasible solutions for problem behaviors. Sample size is typically $20-50$ families, selected for heterogeneity [47]. We adapted the traditional TIPs process by focusing our analysis on the feasibility and acceptability of the newly developed intervention packages and extended the user testing period beyond the usual 5-7 days.

We held to the following key foundational principles throughout the intervention design process: (1) Authentic stakeholder engagement is crucial to the successful design of the intervention, (2) relevant theories of behavior change should inform the design and development of the intervention, (3) the intervention should target individual and/or community-level behavior (versus policy 
Table 1 Final list of targeted nutrition and WASH behaviors

\begin{tabular}{|c|c|}
\hline Behavioral category & Behavior \\
\hline 1. Food preparation and storage & $\begin{array}{l}\text { 1a. Handwashing with soap before food preparation } \\
\text { - Caregiver washes hands with soap before food preparation } \\
\text { 1b. Food safety during preparation } \\
\text { - Food is washed and raw meat is separated from other ingredients } \\
\text { - Food is fully cooked } \\
\text { - Leftover food is reheated after } 4 \mathrm{~h} \text { of initial cooking } \\
\text { - Utensils are fully cleaned and dried } \\
\text { 1c. Food storage } \\
\text { - Stored food is covered } \\
\text { - Stored food is kept in clean container }\end{array}$ \\
\hline 2. Mealtime behaviors & $\begin{array}{l}\text { 2a. Improved dietary diversity } \\
\text { - Improved dietary diversity with locally available foods for pregnant and lactating women } \\
\text { - Improved dietary diversity with locally available foods for children under } 2 \text { using locally available food } \\
\text { - Improved dietary diversity with locally available food for whole family throughout the life course } \\
2 \text { b. Children under } 2 \text { and pregnant and lactating women are given adequate food } \\
\text { - Children under } 2 \text { are fed complementary foods of appropriate thickness } \\
\text { - Children under } 2 \text { are fed complementary foods with appropriate frequency } \\
\text { - Children under } 2 \text { are fed complementary foods in appropriate portions } \\
\text { - Child under } 2 \text { takes extra meal/snack } \\
\text { - Pregnant and lactating women take extra meal/snack } \\
\text { 2c. Feeding based on child-demonstrated hunger } \\
\text { - Caregiver recognizes cues to hunger before child } 0-12 \text { months begins crying (putting fingers in mouth, } \\
\text { spits, looking at others eating) } \\
\text { - Child } 6-24 \text { months is fed slowly and patiently, using eye contact, encouraging and motivating the child } \\
\text { to eat } \\
\text { 2d. Handwashing with soap before feeding and eating } \\
\text { - Caregiver washes hands with soap before eating } \\
\text { - Caregiver washes hands with soap before feeding CU2 } \\
\text { - Caregiver washes child's hands with soap before feeding/eating }\end{array}$ \\
\hline 3. Clean family and home environment & $\begin{array}{l}\text { 3a. Hygienic play environment for children under } 2 \text { years of age } \\
\text { - Rapidly dispose of animal feces in latrine } \\
\text { - Sweeping/cleaning of compound 2-3 times per day } \\
\text { 3b. Safe disposal of child feces } \\
\text { - Caregiver rapidly disposes child feces in latrine } \\
\text { 3c. Handwashing with soap after child feces disposal } \\
\text { - Caregiver washes hands with soap after disposing of child feces } \\
\text { - Caregiver washes child's hands after defecation } \\
\text { 3d. Handwashing with soap after defecation } \\
\text { - Caregiver washes hands with soap after defecation } \\
\text { 3e. Nails are clipped on regular basis } \\
\text { - Caretaker clips child's hands so fingernails do not extend over fingertips }\end{array}$ \\
\hline
\end{tabular}

or physical structures), (4) the intervention must be able to be delivered by trained community health volunteers in the context of the existing intervention (Care Group model), and (5) the intervention must have the potential for sustainability beyond the life of the project.

\section{Results}

\section{Step 1: conduct mixed methods formative research}

The first step in our process, formative research, informed "how best to incorporate aspects of programme design and implementation into the environmental and cultural context" [48-50], (p., 64). This step served to identify the suite of relevant behaviors for action, build the evidence to support pathways of change, and identify existing resources that could support positive behavior change [35]. We conducted formative research in two phases: desk review and primary data collection. We first reviewed the findings of mixed methods research conducted by the THRIVE II program in the program areas of Homa Bay County and Migori County [51]. The desk review served to identify (1) optimal WASH and maternal and child nutrition behaviors with low uptake, (2) the socio-demographic characteristics of the communities, and (3) gaps in understanding key habits, knowledge, beliefs and attitudes, barriers and facilitators to optimal maternal/child nutrition, hygiene, and sanitation behaviors [51]. Findings from the desk review informed the protocols and guiding questions for a second round of ethnographic research that aimed to provide greater contextual detail, clarify key barriers and facilitators of behavior change to infant and young child feeding and WASH-related behaviors, identify messages that resonated with caregivers, explore in more depth the opinions and experiences of caregivers, and determine potential sources of information [52]. Data were collected in six rural communities in Migori $(n=3)$ and Homa Bay Counties $(n=3)$. Data collection consisted of market surveys $(n=4)$; focus group discussions with 
pregnant women and mothers of children under two, fathers, and grandmothers $(n=24)$; key informant interviews with community health workers, community and religious leaders, implementing partners, and staff at the funding agency $(n=29)$; household spot-checks to ascertain WASH hardware and general hygiene $(n=12)$; and structured household observations of WASH and feeding behaviors $(n=24)$. Based on a total of 83 activities that reached 288 study participants, the results indicated a range of barriers and facilitators that influenced families' practice of maternal and child nutrition and WASH behaviors (Table 2). These findings are elaborated elsewhere [52].

\section{Step 2: prioritize target behaviors}

Step 2 served to focus the scope of the intervention by prioritizing target behaviors. Informed by the formative research, we prioritized a preliminary set of nine target behaviors for intervention development: optimal maternal diet, exclusive breastfeeding, optimal complementary feeding, maternal handwashing, washing of children's hands, safe child feces disposal, latrine use, handwashing station presence and use, and food hygiene. Four criteria informed this selection: (1) The behavior was not widely practiced, (2) there were opportunities to integrate behavior-specific activities into current THRIVE II programming, (3) there was plausibility or evidence of the

Table 2 Summary of drivers and barriers to key IYCF and WASH behaviors based on formative research

\begin{tabular}{|c|c|c|}
\hline Key behavior & Barriers & Drivers \\
\hline Infant and young child feeding & $\begin{array}{l}\text { - Belief that eating specific food when pregnant } \\
\text { will result in a too large baby (maternal nutrition) } \\
\text { - Lack of time to breastfeed, prepare } \\
\text { complementary foods multiple times per day, } \\
\text { practice responsive feeding } \\
\text { - Belief that covering hot food will degrade quality }\end{array}$ & $\begin{array}{l}\text { - Caregiver and family member awareness of } \\
\text { critical foods during pregnancy and lactation } \\
\text { (maternal nutrition. } \\
\text { - Knowledge of breastfeeding benefits for CU2 (EBF) } \\
\text { - Access to and knowledge of drying racks } \\
\text { through community strategy (food hygiene) }\end{array}$ \\
\hline Household water treatment & $\begin{array}{l}\text { - Limited access to water } \\
\text { - Unacceptability of chemical treatment taste and smell } \\
\text { - Access to chemicals inconsistent at health } \\
\text { facilities; cost barrier if purchased outside of health } \\
\text { facility } \\
\text { - Perceived lack of time to collect firewood to boil } \\
\text { water }\end{array}$ & $\begin{array}{l}\text { - Knowledge of multiple water treatment } \\
\text { techniques, including: adding alum, boiling, } \\
\text { straining, letting water settle, and treatment with } \\
\text { chemicals (PUR \& Waterguard). } \\
\text { - Perceived importance of cleaning water storage } \\
\text { containers }\end{array}$ \\
\hline Handwashing with soap at critical times & $\begin{array}{l}\text { - Limited access to water and soap. } \\
\text { - Handwashing with soap is not a perceived social } \\
\text { norm. } \\
\text { - Concern that soap or water at handwashing } \\
\text { station will be consumed by animals, stolen, } \\
\text { ruined/damaged by children } \\
\text { - Perceived lack of time to fill handwashing } \\
\text { stations daily }\end{array}$ & $\begin{array}{l}\text { - Convenience of handwashing station } \\
\text { (handwashing station near latrine, access to soap) } \\
\text { - Disgust of feces or dirt on hands } \\
\text { - Caregiver knowledge of when to wash own hands }\end{array}$ \\
\hline Latrine use & $\begin{array}{l}\text { - Lack of household latrines } \\
\text { - Latrine building challenge because of soil, } \\
\text { affordability of materials, and limited skilled } \\
\text { workers } \\
\text { - Public urination and defecation is socially } \\
\text { acceptable. } \\
\text { - Low acceptability of latrines due to smell, } \\
\text { cleanliness, safety, ownership, and distance from } \\
\text { compound }\end{array}$ & $\begin{array}{l}\text { - Privacy during urination and defecation, } \\
\text { particularly of women } \\
\text { - Disgust related to the sight and smell of feces } \\
\text { Perceived fear of catching diseases (e.g. typhoid, } \\
\text { cholera) }\end{array}$ \\
\hline Safe child feces disposal & $\begin{array}{l}\text { - Lack of household latrines } \\
\text { - Lower perceived risk of disease associated with } \\
\text { child feces } \\
\text { - Perceived lack of time for caretakers to supervise } \\
\text { children (do not know where/when child defecates) }\end{array}$ & $\begin{array}{l}\text { - Disgust related to the sight and smell of feces, } \\
\text { presence of flies associated with feces in the } \\
\text { compound } \\
\text { - Caretakers train children to defecate in } \\
\text { designated location }\end{array}$ \\
\hline Promoting clean play environment & $\begin{array}{l}\text { - Uncontained compound animals result in } \\
\text { presence of animal feces } \\
\text { - Lack of commonly understood definition for } \\
\text { "protected play environment" } \\
\text { - Social acceptability of children freely playing } \\
\text { around the compound, uncontained }\end{array}$ & $\begin{array}{l}\text { - Social norm of child playing under caregiver } \\
\text { supervision } \\
\text { - Social norms of keeping a clean compound and } \\
\text { the habit of sweeping driven by feelings of disgust }\end{array}$ \\
\hline Deworming & $\begin{array}{l}\text { - Inconsistent information about dose frequency } \\
\text { being given to caregivers by health workers } \\
\text { - Belief that the costs outweigh the benefits of } \\
\text { taking the medication } \\
\text { - Religion forbidding the use of medication }\end{array}$ & $\begin{array}{l}\text { - Caregivers perceived outcomes as positive for } \\
\text { people that took de-worming medication. } \\
\text { - Knowledge is spread to community by community } \\
\text { health volunteers and community health facility } \\
\text { workers about de-worming medication. }\end{array}$ \\
\hline
\end{tabular}


relationship between the behavior and child stunting based on scientific research, and (4) the potential for changing the behavior was plausible given available resources and the scope of THRIVE II activities. This preliminary list of behaviors evolved over subsequent steps as stakeholders offered continued input, illustrating the iterative nature of this process.

\section{Step 3: use causal analysis to create problem trees}

The aims of step 3 were to clearly articulate problem statements (e.g., handwashing at key times with soap is not practiced), identify strong and weak causal linkages for each of the identified problem behaviors, and create visual diagrams that specified the hierarchy of problems and causes, and cross-causal linkages [35]. We used problem trees to visualize the root and interrelated causes of target problem behaviors for stakeholder engagement. Problem trees are widely used in participatory approaches to develop health promotion interventions in developing countries [53]. The study team used findings from step 1 and the initial list of behaviors identified in step 2 to generate preliminary problem trees for each of the target behaviors, articulating causes at multiple levels (e.g., household, community). The problem trees were then refined during an intensive 3-day workshop with stakeholders, including government workers, local implementing partners, technical experts, and staff members from the NGO central and local office in Kisumu, Kenya.

\section{Step 4: develop solution trees and articulate assumptions and rationales for change}

Following the production of problem trees, stakeholder workshop participants collectively drafted solution trees for each priority behavior, which corresponded to the problem trees. Similar to processes in Intervention Mapping $[54,55]$, solution trees translate the behavioral problems identified in problem trees (i.e., early introduction of non-breastmilk substances) into positive goal statements (i.e., refrains from giving liquids/foods before 6 months of age) [35]. Using a backwards mapping approach [27, 56, 57], positive actions, cognitive processes, and behaviors needed to achieve each of the priority behaviors were mapped. In converting problem trees to solution trees, we recognized the need for greater specificity in how we articulated the problems. For example, in conceptualizing solutions to achieve handwashing goals, we noted that "key times" for handwashing mattered and thus required narrower categories and specification (e.g., "caretakers wash hands with soap before eating" or "caretakers wash hands with soap before preparing food").

Stakeholders reviewed solution trees during the 3-day workshop, identified needed revisions, and voted on priority behavioral determinants based on feasibility within the programming context and potential for change.
Additional behavioral determinants linked to the potential for impact on stunting were identified during the post-workshop revision process. Once completed, each solution tree included multiple, linked levels of motivational, cognitive, and behavioral solutions phrased as goal statements (e.g., caregivers are motivated to wash hands; caregivers have access to soap) that if achieved would theoretically result in the practice of the priority behavior (e.g., caretakers wash hands with soap before eating). A final, collective review of the solution trees and goal statements eliminated those that would be outside of the scope of the project due to budget, time, existing programming, staff expertise, or those that did not align with the aims of creating a behavioral intervention (e.g., a policy-level intervention or a major structural intervention altering the environment).

\section{Step 5: link the solution trees to intervention functions}

Step 5 served to verify the hypothesized pathways of change articulated in the solution trees and to link goal statements, COM-B components, theoretical domains, and intervention functions [36]. Two team members independently mapped each goal statement (e.g., caretakers wash hands with soap before eating) with behavioral determinants from the solution trees (e.g., washing hands before food preparation is perceived as convenient) onto one of the six corresponding COM-B components (e.g., reflective motivation). Mapping outputs were compared and assessed for consistency across researchers.

Next, we applied the theoretical domain framework (TDF) to each of the goal statements and the determinants identified in the solution trees [36]. The TDF, developed and validated through systematic review and consensus analysis, includes 128 explanatory constructs from 33 behavior change theories $[58,59]$. It serves as an integrative framework synthesizing important constructs across many relevant theories, comprising 14 domains, including knowledge, skills, beliefs about capabilities, reinforcement, etc. The COM-B components served as a "cross-walk" linking the goal statements and their determinants to the TDFs. After mapping the domains to the goal statements and determinants, we identified specific intervention functions (e.g., education, persuasion, modeling) that corresponded with the relevant TDF. The culminating product of this process was an intervention function table (Table 3). When shared with Catholic Relief Services, they encouraged the inclusion of more behaviors that they felt would be manageable and critical given the local context. This negotiation ended with the addition of behaviors that would pointedly address environmental hygiene in the compound, as well as expanding upon handwashing and food hygiene behaviors (Table 1). Additional problem and solution trees were then developed, and step 5 was repeated for these new behaviors $[58,59]$. 


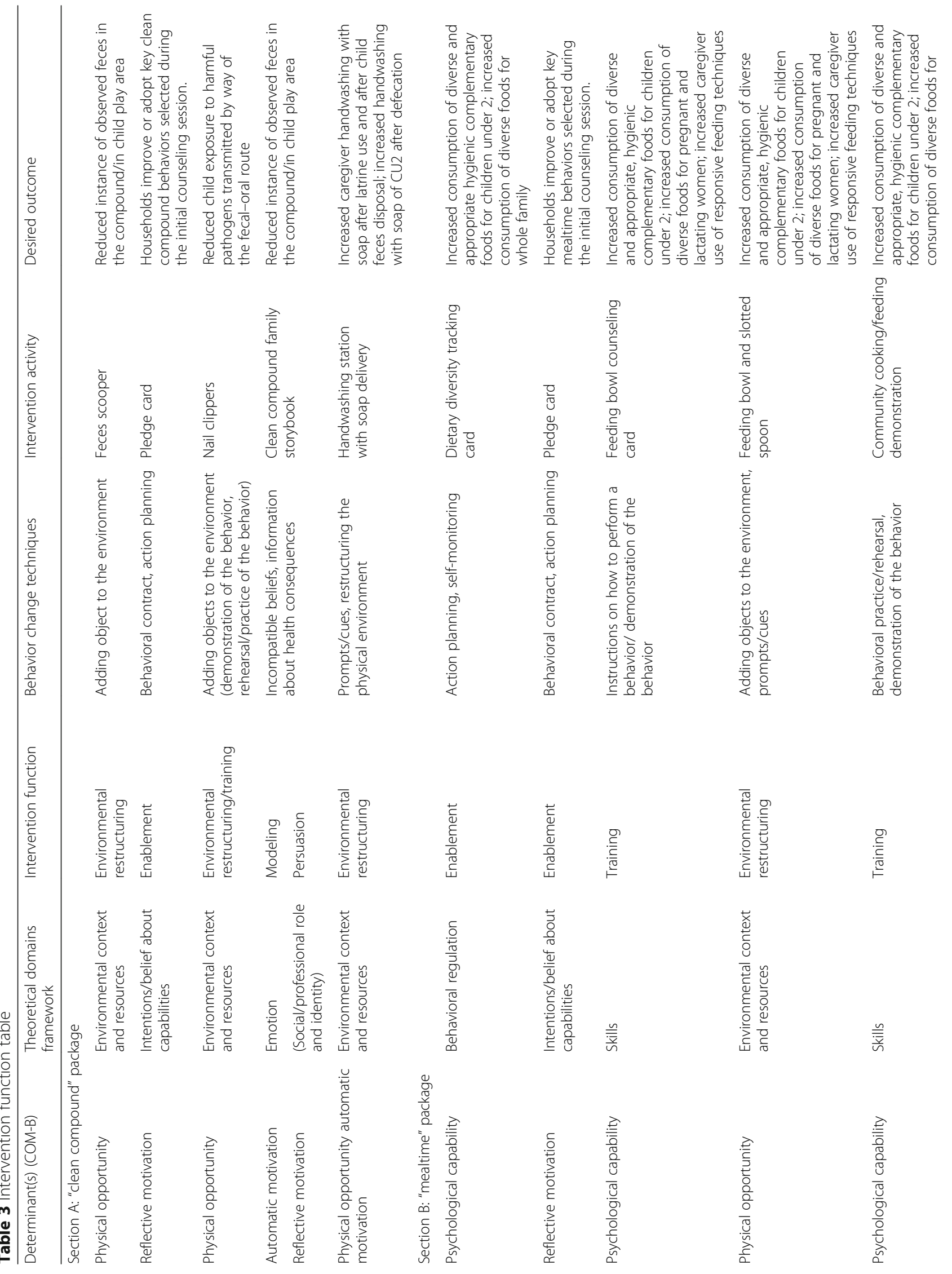




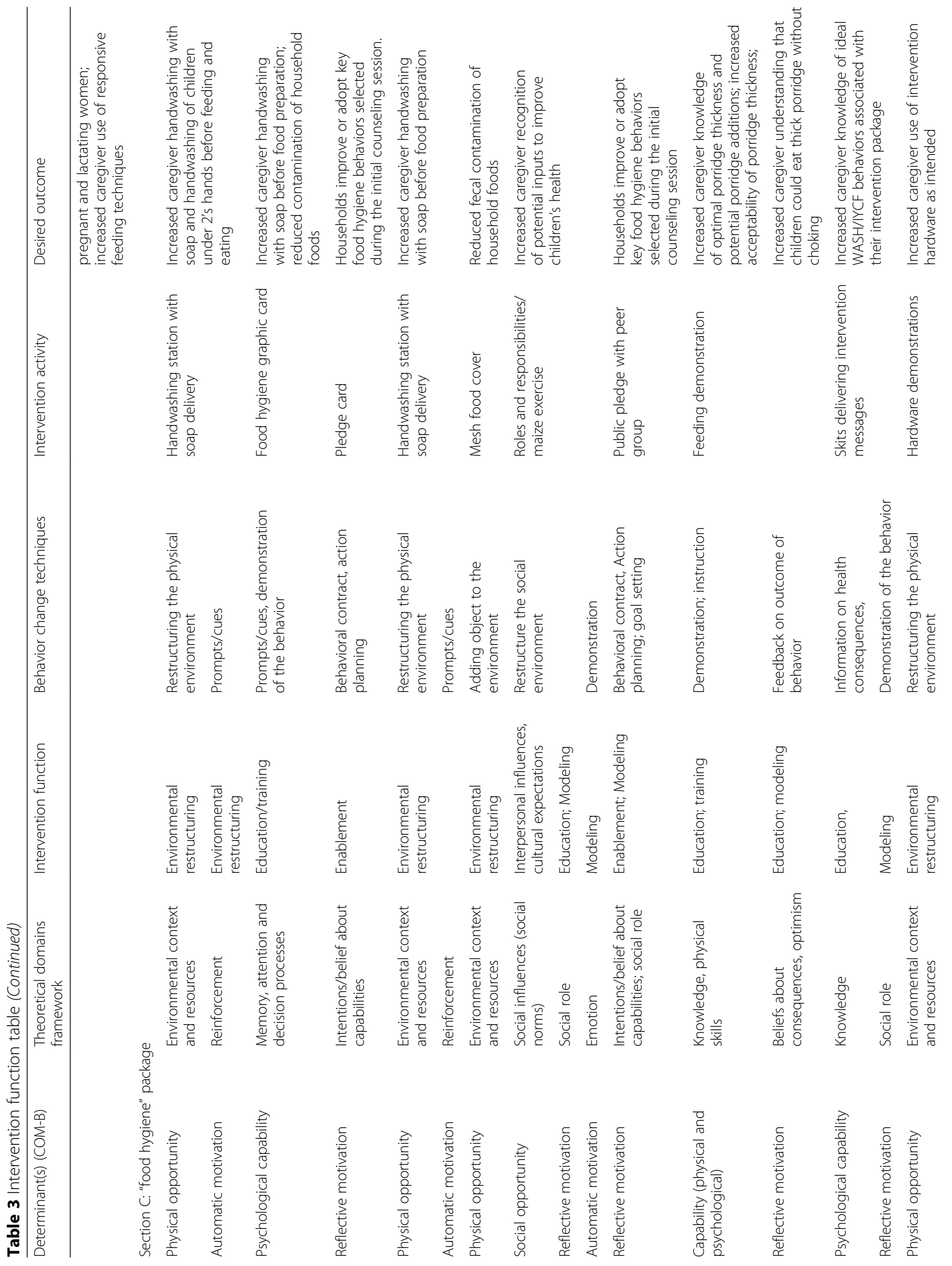




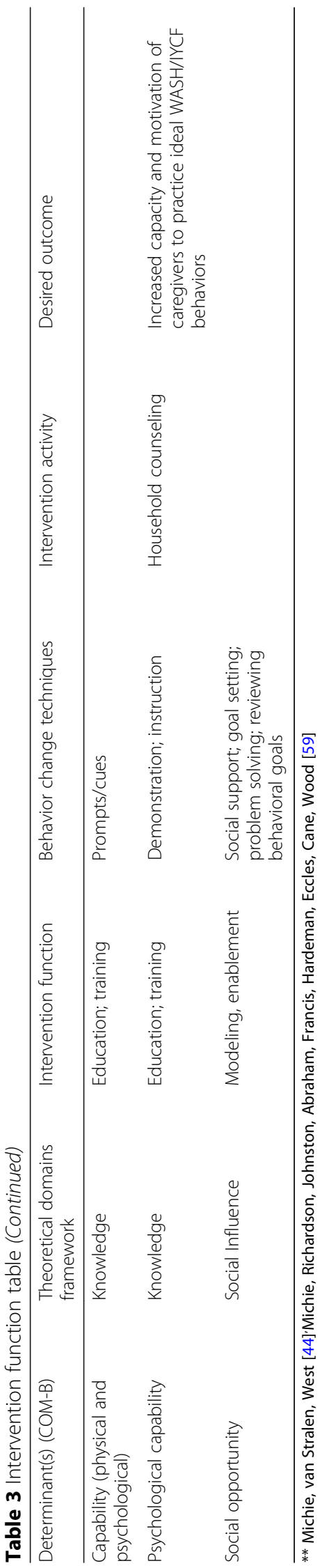




\section{Step 6: develop the intervention plan}

The aim of step 6 was to identify potential behavior change techniques that would utilize the intervention functions to reach our desired outcomes. The use of the overall delivery modality-the THRIVE II Care Group model-was pre-specified as part of the overarching intervention plan. Beyond this approach, we could develop new social behavior change communication material targeting community stakeholders (e.g., fathers). We narrowed potential intervention approaches and outputs by triangulating information from steps 1 to 5 . Next, we identified the behavior change techniques that corresponded with the intervention functions selected in step 5. Behavior change techniques can be described as "observable, replicable, and irreducible component of an intervention designed to alter or redirect causal processes that regulate behavior" [60]. We reviewed the literature on WASH and nutrition-sensitive behavior change projects with similar desired outcomes. We analyzed elements of these interventions by applying the same taxonomy and steps (described in step 5) to the intervention components to understand what had been effective in other locations and which behavior change techniques had potentially informed activities within successful interventions [22, 60-65].

\section{Step 7: determine the intervention activities}

The objective of this step was to develop specific intervention activities and package them thematically. We developed intervention tables to show the connection between the positive health goal statement from our solution trees with COM-B domains, the TDF, intervention functions, and behavior change techniques. In determining what the intervention activities would be, there was a need to address the challenge of impacting multiple behaviors within the limited timeframe of TIPs without reducing participants' capability and motivation to practice desired behaviors. Since the behaviors were linked to daily household activities, we grouped them into three separate thematic packages. The "clean compound" package (Table 3, Section A) aimed to improve compound environmental hygiene to reduce children's exposure to animal and human feces. The "mealtime" package (Table 3, Section B) aimed to improve caretaker behaviors that related to household eating and feeding times. The "food hygiene" package (Table 3, Section C) aimed to improve caretaker behaviors related to safe food preparation and storage.

After grouping behaviors together, we assessed which behavior change techniques were most appropriate for each behavioral outcome, what potential activities would come from behavior change techniques and how they could be adapted within the Care Group model. For example, the COM-B domain of social opportunity was addressed by incorporating grandmothers and fathers into community and household activities. The behavior change technique of social opportunity was approached through activities encouraging lead mothers to model these behaviors in their community.

\section{Step 8: test and refine intervention packages}

We adapted TIPs to test and refine the intervention packages in the context of the Care Group model. Six neighbor groups from Homa Bay $(N=3)$ and Migori $(N=3)$ counties were evenly distributed to one of the three intervention packages. Fathers and grandmothers were included in community and household events. Trials of improved practices were implemented over 5 weeks. Trained research assistants, community health workers, and family members participated in a community event to (1) raise awareness of the assigned intervention package, (2) explore family members' roles and contributions to child health, (3) share knowledge on targeted practices of their intervention arm (see Table 3), and (4) make a public pledge of commitment to improve practices. Research assistants conducted three household visits. First, research assistants documented current behaviors, introduced intervention materials, targeted behaviors for change, discussed tailored strategies for behavior change, and recorded participant pledges to practice behavior. After 3 weeks, research assistants monitored use of materials, problem-solved challenges, addressed knowledge gaps, and encouraged participants to maintain behaviors. At 5 weeks, researchers collected participant feedback on the intervention package including delivery, materials, strengths, and weaknesses; recorded participant uptake of key messages; and documented behavior change. Focus group discussions with mothers $(N=6)$ assessed participant acceptability of messages and materials, and family participation and engagement in the promoted practices.

Findings from TIPs demonstrated that thematic packaging of behavior change strategies assisted people in adopting more than one behavior. Some strategies necessitated change: we emphasized social opportunity in TIPs to overcome specific physical opportunity barriers (e.g., time, money, access to economic opportunities). To achieve this, we included fathers and grandmothers in activities and utilized social norms, pressures, and people's roles towards their child(ren) to encourage all caregivers to change behaviors. However, fathers and grandmothers found it difficult to attend household counseling sessions. Mothers were influenced by other women, whether neighbors, co-wives, or community health workers.

We adapted the TIPs approach to accommodate the Care Group model and emphasize the social relations of female peers. To achieve this aim, we strengthened local capacity by including community health workers and 
care group women in a general training that focused on increasing knowledge related to the three intervention packages, and building facilitation and counseling skills. Based on reported behavior changes during TIPs, caregiver interest in the other intervention packages, and our intent to design an integrated infant and young child feeding and WASH intervention, we ultimately combined the three packages into a single behavior change strategy that would introduce one intervention package each month through neighbor women meetings and household counseling [66].

\section{Discussion}

Due to its complex etiology, reductions in child stunting of the magnitude targeted for the Sustainable Development Goals requires the integration of multiple sectors [10]. When designed and implemented well, WASH strategies can reduce the burden of diarrheal diseases $[22,24,67]$, though there has been little evidence of reducing asymptomatic chronic infections, and stunting reduction has not been demonstrated [22, 23]. To do so, interventions must achieve better adherence and sufficiently block relevant transmission pathways [68]. Health sector and mass media interventions can improve child feeding and nutrient intakes [69-72], and agriculture sector approaches may create an enabling food environment by improving diet quality, quantity, and safety $[10,11,73]$. Despite statistical significance, the impacts of direct nutritional programs to reduce stunting are relatively modest. Researchers attribute these modest impacts to several issues including limited multi-sectorial integration, limited application of contextually relevant and theoretically based behavior change theories and approaches [32, 41, 74-76], and the underutilization of theories of change in intervention design [28].

In reviewing the social/behavior change research literature, we noted that the experiences described in this paper aligned with several consistently cited recommendations for stunting prevention programs. They include the following:

(1) Programs should be multi-sectorial to address multiple etiologies and include both communitybased and family-focused approaches to reach not only mothers but also other influential family members such as fathers and mothers-in-law, peers, and policy makers [10, 54, 61, 74, 77-79].

(2) Multi-sectoral interventions should be delivered in an integrated way that accounts for the lived experience, daily routines, and repeated behaviors of the caregivers who may be the sources of pathogen exposure and thus are expected to change behaviors [26, 80].

(3) A deep understanding of context through formative research should inform intervention design and
TOC development; the process for linking formative research findings to intervention components should be systematic and clearly articulated [28, 32, 50, 74, 81].

(4) An evidence-based and theory-informed TOC should guide intervention design and be used throughout the program life cycle including implementation, monitoring, and evaluation $[28,29,33,39,54,82]$.

(5) Intervention design should be grounded in behavior change theories; these theories should be explicitly articulated and utilized in the design of the theory of change [29, 54, 74, 83].

(6) Interventions should be multi-level and multicomponent integrating several relevant behavior change theories and including activities that target multiple (i.e., 2 or more) domains beyond knowledge generation [29, 54, 84, 85].

(7) Interventions should engage not only phases of volitional behavior but maintenance as well, with potentially different but relevant theories and activities for each phase [86].

(8) Pilot-testing should be conducted prior to larger scale implementation and testing to allow for refinement and revision of behavior change strategies and theories of change [47].

(9) Stakeholders should be engaged in the development of the TOC and the design, implementation, and evaluation of interventions [28, 34].

To achieve alignment with these recommendations, our process adapted and integrated four methodsethnographic formative research [50], an iterative and participatory process to develop the intervention's theory of change [35], a systematically developed and evidencebased behavior change mapping exercise to identify intervention approaches and components [36], and behavioral micro-trials to design and pilot intervention components [47]. The formative research conducted for our work aimed to provide rich contextual information on the physical and social opportunity domains of our priority behaviors. It also provided deeper understanding of the motivations and capabilities that influenced behavior and highlighted the most appropriate community and family-focused activities and delivery platforms, including daily routines for integration. The findings of our formative work directly informed our iterative process to select priority behaviors, develop problem and solution trees for each behavior, and identify intervention packages and behavior change strategies most appropriate for the study context.

The BCW [36] served as a starting point for our work and a framework to identify relevant behavior change domains and the most appropriate techniques for achieving change of target behaviors in the study context 
(recommendation 5, above). For complex behaviors, such as those related to diet or WASH, the BCW approach recommends using the TDF to gain greater specificity in terms of the needed behavior changes. Collectively, this process is analogous to steps $3-5$ in our process (Fig. 1). The application of the COM-B model, and subsequently the TDF to add greater specificity, mitigated the potential for an overly narrow focus that may arise in selecting and applying a single behavioral or behavior change theory to a complex behavior change problem $[42,58,59]$. Following detailed specification of the behaviors that required change, relevant and appropriate intervention functions were mapped to behavior change techniques to support development of intervention activities (i.e., steps 6 and 7, Fig. 1). While the $\mathrm{BCW}$ is a relatively new framework for intervention design, it has been used to characterize behavioral problems and develop interventions targeting both individual- and population-level health outcomes in the fields of mental health, nutrition and physical activity, smoking cessation, and improving provision of care by physicians and nurses [36]. While the bulk of $\mathrm{BCW}$ applications are in developed countries, examples exist from Thailand [87] and Kenya [88].

Many interventions in low- and middle-income countries targeting WASH and nutrition are criticized for their limited application of contextually grounded behavior change theories or inappropriate use of a single theory in intervention design [74]. Use of the BCW helps avoid these pitfalls through the use of context, most notably the social and environmental opportunities domain of the COM-B model, as a starting point and the integration of multiple behavior change theories to inform intervention design.

To be impactful, research suggests that interventions should focus intensively on a few key behaviors, integrate these into familiar routines, and appeal not only to early adopters, but also laggards and late adopters [26, 36, 74]. Through our intervention development process, we identified three intervention packages that were thematically coherent; each package focused on a series of behavior change activities that collectively served to motivate adoption of a set of thematically linked behaviors. The prioritized behaviors were grouped in ways that integrated into daily household routines, based either on performance at similar times of day or in similar locations. This routinefocused approach differs from the traditional siloing of WASH and nutrition messages based on behavioral outcomes. For example, messages around washing hands before eating were paired with mealtime behaviors, not other handwashing behaviors. Our approach allowed us to integrate multiple layers of intervention functions to reinforce behavior adoption and maintenance.

We used an adapted TIPs [47] approach to test the feasibility, acceptability, and potential effectiveness of the components of the intervention packages prior to larger scale testing. Through TIPs, we found that such thematic packaging enabled adoption of behaviors. However, the

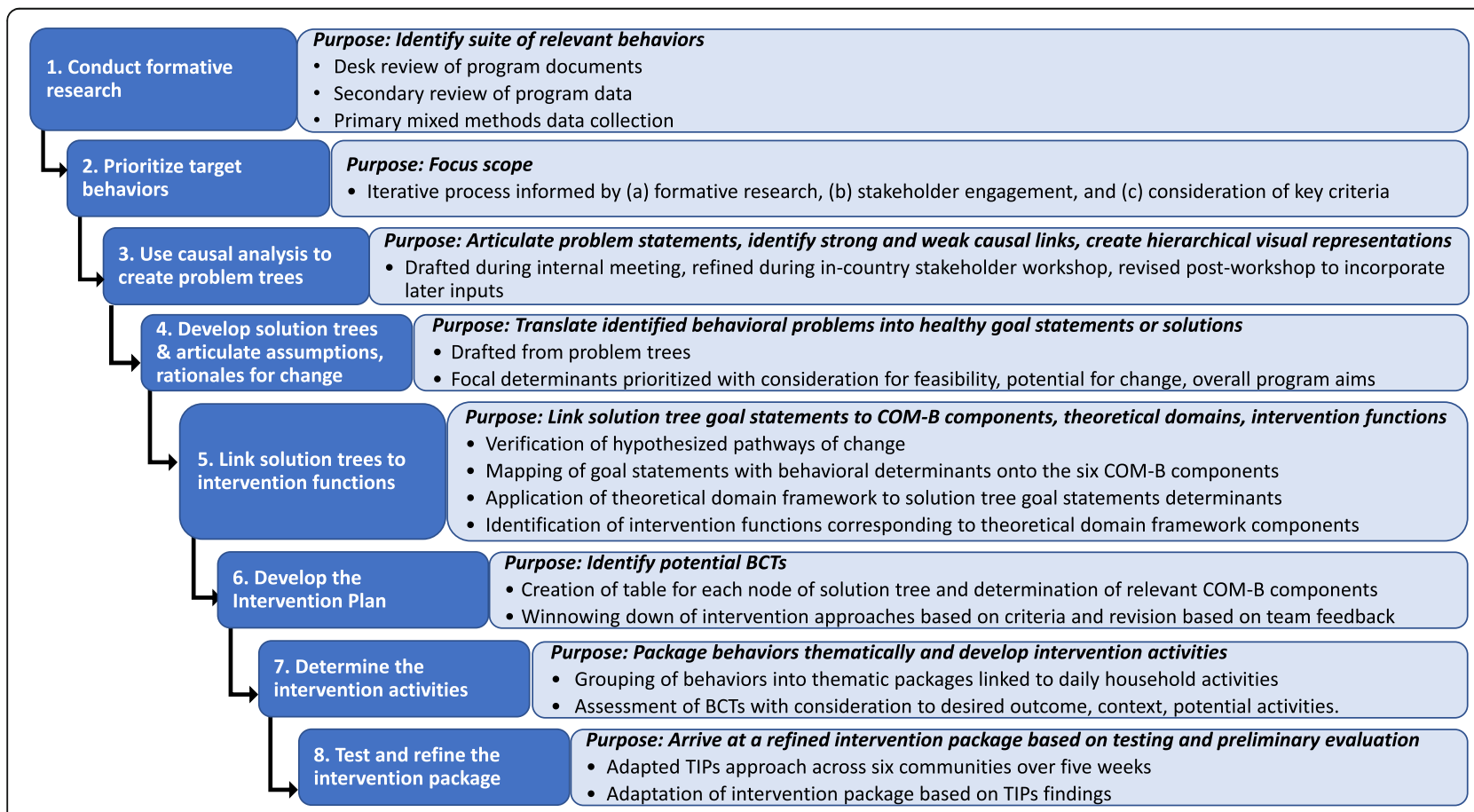

Fig. 1 Eight-step process for intervention development and refinement. BCTs Behavior change techniques; COM-B Capability/opportunity/ motivation behavioral model; TIPS Trials of improved practices 
short duration and small sample of TIPs precluded us from examining behavior maintenance over a sustained period or assessing intervention outcomes.

TOCs, developed in the tradition of theory-driven evaluation, describe the underlying assumptions and hypothesized pathways by which programs achieve impacts-the how and the why of program impact. TOCs have multiple uses in the program life cycle but are often underutilized in program design and implementation [28]. Similarly, few programs describe in detail the process used to create their TOC. We adapted an existing framework and process for TOC development [35] and used a systematic behavioral mapping approach [36] to articulate rationales for our pathways to change (recommendation 4), although these methods could be applied to a range of different types of programs. TOCs can be used as "living" tools that adapt in response to lessons learned over the implementation period. In this project, TIPs served as a precursor to this adaptation process. As we have scaled the finalized intervention packages for larger implementation and testing, we have continued to revisit the TOC.

We recognized that stakeholder engagement in all aspects of our intervention development process would be crucial to ensure the intervention packages would be relevant and realistic to integrate into existing program context, sustainable and scalable. We sought a variety of relevant stakeholder perspectives that included topical (WASH, nutrition, behavior change), programmatic (country director, monitoring and evaluation experts, program managers), and contextual (local academic partner, local partner organizations) expertise and experiences. Stakeholders were engaged through participatory workshops, monthly conference calls, and feedback integration at each stage of the process. While some activities were inherently collaborative in nature, others more closely resembled a system of product review, provision of feedback, and subsequent revision. Applying stakeholder feedback to the development of interventions in other areas would likely involve other differences in how stakeholders are engaged.

\section{Strengths, limitations, and challenges}

Our intervention design process had several limitations worth noting. First, the process of finalizing the behaviors to focus on was iterative, which is both a strength and a limitation. As a strength, it allowed for the voices of relevant stakeholders to be taken into consideration. But as a limitation, it served as a "constantly moving target"; as behaviors were continually refined, so too did the need to refine the foundational work (i.e., the problem and solution trees), the intervention functions, and even the intervention plan.
Second, we deliberately developed this intervention within the context of the Care Group model. Though it enhanced the potential for scale, this decision limited the nature of the intervention activities as this model targets individual- and/or community-level behaviors (versus policy or physical structures). Adherence to these criteria limited our ability to fully elaborate interventions based on our application of the $\mathrm{BCW}$ approach, especially as they pertain to creating an enabling environment for change. For example, environmental opportunities that influence diet practices, such as food accessibility and affordability, could be enhanced through policy levers including for example, subsidies for high-quality foods (i.e., a fiscal measure in BCW vernacular) or enhanced agriculture extension (i.e., service provision). Large scale mass media efforts can effectively shift social norms and behaviors [32, 63, 77-79] and may be useful for inculcating and reinforcing handwashing and feces disposal. Similarly, platforms that use the education sector to target schoolaged children can shift beliefs, attitudes, and practices in the home [89]; however, these were outside the scope of the THRIVE II delivery platform.

Third, it is unclear the extent to which the intervention that was developed is generalizable beyond western Kenya. On the one hand, the extensive formative research ensures that the intervention is sensitive to context, but in doing so, it may be less applicable in contexts outside of this setting. Future work will hopefully allow us to test and modify the approach; the process laid out in this manuscript provides a roadmap. Finally, examining the approaches as a complete set of intervention packages masks whether there are subcomponents that are more or less effective at generating behavioral change. A dismantling research design in which individual intervention components are tested separately (or in subsets) would be needed to more fully answer this question.

\section{Conclusions}

We have outlined our approach to developing a theoryand evidence-based intervention that integrated a set of WASH and nutrition behaviors to target growth shortfalls among young children in western Kenya. Interventions, specifically in the WASH and nutrition sectors are not typically developed in such a prescriptive way, yielding poor sustainability and sub-optimal health gains. An approach that equally values peer-reviewed evidence and stakeholder inputs, and that adheres to a structured and deliberate theory-based process may provide the best opportunity to achieve interventions that result in sustained behavior change at scale. We hope that in laying out this step-by-step process, others may use and modify our approach to support rigorous program design in a range of other areas of needed behavior change. 


\section{Abbreviations}

BCW: Behavior change wheel; COM-B: Capability, opportunity, motivationbehavior; TDF: Theoretical domain framework; TIP: Trials of improved practice; TOC: Theory of change; WASH: Water, sanitation, and hygiene

\section{Acknowledgements}

Catholic Relief Services was the main implementing partner; the Conrad N. Hilton Foundation provided the funding for the work. Vanessa Tobin developed an initial scoping document that outlines synergies between WASH and nutrition and supported early stages of the project as the Chief of WASH for CRS. Catholic Relief Services: Maureen Kapiyo, David Leege, Elena McEwan, Fidelis Muthoni, Raphael Ofware, George Okoth; Emory University: Maryann Delea, Ellah Kadera, Alysse Kowalski, Molly Linabarger, Sandra Gomez Ventura, Breanna Wodnik; Homa Hills Community Development Organization: Dennis Ochieng, Evelyne Otieno, Stephan Owino; Mercy Orphans: Tobias Ogaga, Josephine Okomo, Phenny Ogweno, Judith Wara; and Uzima University: Dorothy Adhiambo, Lydia Atetwe, Lily Lukorito, Nicanor Muga, Richard Muga, Jacqueline Okumu, Fredrick Okumu, Rosebel Ouda, and Nancy Oyugi.

\section{Authors' contributions}

KRJA conceptualized the scope of the paper. MCF developed the scope of the overall project. KRJA, AE, AWG, EEM, and AWG wrote the first draft of the manuscript. AE and EAO collected and managed formative research and TIPs. AE, EAO, MCF, KRJA, and AWG led problem and solution tree development and refinement. AE and EEM connected solution trees to intervention functions (Table 3). $\mathrm{AE}, \mathrm{EAO}$, and EEM created intervention design and protocol for TIPS, and reviewed by MCF. All authors reviewed the manuscript, gave feedback and provided guidance for the final manuscript. All authors read and approved the final manuscript.

\section{Funding}

This research was sponsored by Catholic Relief Services as a part of a project funded by Conrad N. Hilton Foundation.

\section{Availability of data and materials}

The datasets used and/or analyzed during the current study are available from the corresponding author on reasonable request.

\section{Ethics approval and consent to participate}

All research activities were reviewed and approved by the Great Lakes University of Kenya Ethical Review Board; Kenya National Commission for Science, Technology and Innovation Review Board; and Emory University Institutional Review Board (no. IRB00090057). All participants provided written informed consent and received an additional information sheet for their reference.

\section{Consent for publication}

Not Applicable

\section{Competing interests}

The authors declare they have no competing interests.

\section{Author details}

'Department of Behavioral Sciences and Health Education, Rollins School of Public Health, Emory University, Atlanta, GA, USA. ²Department of Environmental Health, Rollins School of Public Health, Emory University, Atlanta, GA, USA. ${ }^{3}$ Hubert Department of Global Health, Rollins School of Public Health, Emory University, Atlanta, GA, USA.

\section{Received: 14 February 2019 Accepted: 23 January 2020}

\section{Published online: 03 February 2020}

\section{References}

1. Black RE, Victora CG, Walker SP, Bhutta ZA, Christian P, de Onis M, et al. Maternal and child undernutrition and overweight in low-income and middle-income countries. Lancet. 2013;382(9890):427-51.

2. Bhutta ZA, Das JK. Global burden of childhood diarrhea and pneumonia: what can and should be done? Pediatrics. 2013;131(4):634-6.

3. McGovern ME, Krishna A, Aguayo VM, Subramanian SV. A review of the evidence linking child stunting to economic outcomes. Int J Epidemiol. 2017.
4. Hoddinott J, Alderman H, Behrman JR, Haddad L, Horton S. The economic rationale for investing in stunting reduction. Matern Child Nutr. 2013; 9(Suppl 2):69-82.

5. Hoddinott J, Behrman JR, Maluccio JA, Melgar P, Quisumbing AR, RamirezZea $\mathrm{M}$, et al. Adult consequences of growth failure in early childhood. Am J Clin Nutr. 2013;98(5):1170-8.

6. International Food Policy Research Institute. Global nutrition report 2016: from promise to impact: ending malnutrition by 2030. Washington, DC; 2016.

7. de Onis M, Dewey KG, Borghi E, Onyango AW, Blossner M, Daelmans B, et al. The World Health Organization's global target for reducing childhood stunting by 2025: rationale and proposed actions. Matern Child Nutr. 2013; 9(Suppl 2):6-26.

8. Bhutta ZA, Das JK, Rizvi A, Gaffey MF, Walker N, Horton S, et al. Evidencebased interventions for improvement of maternal and child nutrition: what can be done and at what cost? Lancet. 2013:382(9890):452-77.

9. Casanovas Mdel C, Lutter CK, Mangasaryan N, Mwadime R, Hajeebhoy N, Aguilar AM, et al. Multi-sectoral interventions for healthy growth. Matern Child Nutr. 2013;9(Suppl 2):46-57.

10. Ruel MT, Alderman H, Maternal Child Nutrition Study Group. Nutrition-sensitive interventions and programmes: how can they help to accelerate progress in improving maternal and child nutrition? Lancet. 2013:382(9891):536-51.

11. Girard AW, Self JL, McAuliffe C, Olude O. The effects of household food production strategies on the health and nutrition outcomes of women and young children: a systematic review. Paediatr Perinat Epidemiol. 2012; 26(Suppl 1):205-22.

12. Hoffman D, Cacciola T, Barrios P, Simon J. Temporal changes and determinants of childhood nutritional status in Kenya and Zambia. J Health Popul Nutr. 2017:36(1):27.

13. Wendt A, Gibbs CM, Peters S, Hogue CJ. Impact of increasing interpregnancy interval on maternal and infant health. Paediatr Perinat Epidemiol. 2012;26(Suppl 1):239-58.

14. van den Bold M, Quisumbing AR, Gillespie S. Women's empowerment and nutrition: an evidence review; 2013

15. Nqure FM, Reid BM, Humphrey JH, Mbuya MN, Pelto G, Stoltzfus RJ. Water sanitation, and hygiene (WASH), environmental enteropathy, nutrition, and early child development: making the links. Ann N Y Acad Sci. 2014;1308:118-28.

16. Spears D, Ghosh A, Cumming O. Open defecation and childhood stunting in India: an ecological analysis of new data from 112 districts. PLoS One. 2013;8(9):e73784.

17. Penakalapati G, Swarthout J, Delahoy MJ, McAliley L, Wodnik B, Levy K, et al. Exposure to animal feces and human health: a systematic review and proposed research priorities. Environ Sci Technol. 2017;51(20):11537-52.

18. Checkley W, Buckley G, Gilman RH, Assis AM, Guerrant RL, Morris SS, et al. Multi-country analysis of the effects of diarrhoea on childhood stunting. Int J Epidemiol. 2008;37(4):816-30.

19. Bethony J, Brooker S, Albonico M, Geiger SM, Loukas A, Diemert D, et al. Soil-transmitted helminth infections: ascariasis, trichuriasis, and hookworm. Lancet. 2006;367(9521):1521-32.

20. Crane RJ, Jones KD, Berkley JA. Environmental enteric dysfunction: an overview. Food Nutr Bull. 2015;36(1 Suppl):S76-87.

21. Mbuya MN, Humphrey JH. Preventing environmental enteric dysfunction through improved water, sanitation and hygiene: an opportunity for stunting reduction in developing countries. Matern Child Nutr. 2016; 12(Suppl 1):106-20.

22. Luby SP, Rahman M, Arnold BF, Unicomb L, Ashraf S, Winch PJ, et al. Effects of water quality, sanitation, handwashing, and nutritional interventions on diarrhoea and child growth in rural Bangladesh: a cluster randomised controlled trial. Lancet Glob Health. 2018;6(3):e302-e15.

23. Null C, Stewart CP, Pickering AJ, Dentz HN, Arnold BF, Arnold CD, et al. Effects of water quality, sanitation, handwashing, and nutritional interventions on diarrhoea and child growth in rural Kenya: a clusterrandomised controlled trial. Lancet Glob Health. 2018;6(3):e316-e29.

24. Freeman MC, Garn JV, Sclar GD, Boisson S, Medlicott K, Alexander KT, et al. The impact of sanitation on infectious disease and nutritional status: a systematic review and meta-analysis. Int J Hyg Environ Health. 2017;220(6):928-49.

25. Prendergast AJ, editor. The sanitation hygiene infant nutrition efficacy (SHINE) trial: what's next? Baltimore: American Society of Tropical Medicine and Hygiene; 2017.

26. Menon P, Frongillo EA. Can integrated interventions create the conditions that support caregiving for better child growth? Lancet Glob Health. 2018; 6(3):e236-e7. 
27. De Silva MJ, Breuer E, Lee L, Asher L, Chowdhary N, Lund C, et al. Theory of Change: a theory-driven approach to enhance the Medical Research Council's framework for complex interventions. Trials. 2014;15:267.

28. Breuer $\mathrm{E}$, Lee L, De Silva M, Lund C. Using theory of change to design and evaluate public health interventions: a systematic review. Implement Sci. 2016;11:63.

29. Briscoe C, Aboud F. Behaviour change communication targeting four health behaviours in developing countries: a review of change techniques. Soc Sci Med. 2012;75(4):612-21.

30. Pelto GH, Martin SL, Van Liere M, Fabrizio CS. The scope and practice of behaviour change communication to improve infant and young child feeding in low- and middle-income countries: results of a practitioner study in international development organizations. Matern Child Nutr. 2016;12(2):229-44.

31. Pelto GH, Martin SL, van Liere MJ, Fabrizio CS. Perspectives and reflections on the practice of behaviour change communication for infant and young child feeding. Matern Child Nutr. 2016;12(2):245-61

32. Graziose MM, Koch PA, Wang YC, Lee Gray H, Contento IR. Costeffectiveness of a nutrition education curriculum intervention in elementary schools. J Nutr Educ Behav. 2017:49(8):684-91 e1.

33. Lutter CK, lannotti L, Creed-Kanashiro H, Guyon A, Daelmans B, Robert R, et al. Key principles to improve programmes and interventions in complementary feeding. Matern Child Nutr. 2013;9(Suppl 2):101-15.

34. Mayne J. Useful Theory of Change models. Can J Prog Eval. 2015;30(2):119-42.

35. Starr L, Fornoff M. Theory of Change: facilitator's guide. Washington, DC: TANGO International and The Technical and Operational Performance Support (TOPS) Program; 2016.

36. Michie S, Atkins L, West R. The Behavior Change Wheel: a guide to designing interventions. Great Britain: Silverback Publishing; 2014

37. Hailemariam M, Fekadu A, Selamu M, Alem A, Medhin G, Giorgis TW, et al. Developing a mental health care plan in a low resource setting: the theory of change approach. BMC Health Serv Res. 2015;15:429.

38. Vogel I. Review of the use of 'Theory of Change' in international development: review report: UK Department of International Development; 2012.

39. Mayne J, Johnson N. Using theories of change in the CGIAR Research Program on Agriculture for Nutrition and Health Evaluation. 2015;21(4):407-28.

40. Retolaza I. Theory of Change: a thinking and action approach to navigate in the complexity of social change processes: Humanist Institute for Development Cooperation; 2011.

41. Rothschild ML. Carrrots, sticks, and promises: a conceptual framework for the management of public helath and social issue behaivors. J Market. 1999;63(4):24-37.

42. Michie S, van Stralen MM, West R. The behaviour change wheel: a new method for characterising and designing behaviour change interventions. Implement Sci. 2011;6:42.

43. Michie S, Carey RN, Johnston M, Rothman AJ, de Bruin M, Kelly MP, et al From theory-inspired to theory-based interventions: a protocol for developing and testing a methodology for linking behaviour change techniques to theoretical mechanisms of action. Ann Behav Med. 2016.

44. Michie S, Wood CE, Johnston M, Abraham C, Francis JJ, Hardeman W. Behaviour change techniques: the development and evaluation of a taxonomic method for reporting and describing behaviour change interventions (a suite of five studies involving consensus methods, randomised controlled trials and analysis of qualitative data). Health Techno Assess. 2015;19(99):1-188.

45. Hoddinott P. A new era for intervention development studies: BioMed Central; 2015.

46. Perry H, Morrow M, Borger S, Weiss J, DeCoster M, Davis T, et al. Care Groups I: An innovative community-based strategy for improving maternal, neonatal, and child health in resource-constrained settings. Glob Health Sci Pract. 2015;3(3):358-69.

47. The Manoff Group. Trials of improved practices (TIPs): giving participants a voice in program design. Washington, DC: The Manoff Group; 2005.

48. Bentley ME, Johnson SL, Wasser H, Creed-Kanashiro H, Shroff M, Fernandez Rao $S$, et al. Formative research methods for designing culturally appropriate, integrated child nutrition and development interventions: an overview. Ann N Y Acad Sci. 2014;1308:54-67.

49. Bentley ME, Wasser HM, Creed-Kanashiro HM. Responsive feeding and child undernutrition in low- and middle-income countries. J Nutr. 2011;141(3):502-7.

50. Tumilowicz A, Neufeld LM, Pelto GH. Using ethnography in implementation research to improve nutrition interventions in populations. Matern Child Nutr. 2015;11(Suppl 3):55-72.
51. Sombe M, Oindo C. THRIVE II project in Kenya: baseline survey final report: CRS; 2016

52. Ellis A, McClintic E, Awino E, Webb-Girard A, Freeman M. Drivers and barriers related to WASH and infant and young child feeding in Migori and Homa Bay. Kenya: Emory University; 2017.

53. Snowdon W, Schultz J, Swinburn B. Problem and solution trees: a practical approach for identifying potential interventions to improve population nutrition. Health Promot Int. 2008;23(4):345-53.

54. Brug J, Oenema A, Ferreira I. Theory, evidence and Intervention Mapping to improve behavior nutrition and physical activity interventions. Int J Behav Nutr Phys Act. 2005;2(1):2.

55. Bartholomew Eldredge LK, Parcel GS, Kok G, Gottlieb NH. Intervention Mapping: designing theory and evidence-based health promotion programs. 1st ed: The McGraw-Hill Companies; 2001

56. Taplin $\mathrm{DH}$, Clark H. Theory of Change basics: a primer on Theory of Change. ActKnowledge: New York; 2012.

57. Taplin DH, Clark H, Collins E, Colby DC. Theory of Change technical papers: a series of papers to support development of Theories of Change based on practice in the field. ActKnowledge: New York; 2013.

58. Cane J, O'Connor D, Michie S. Validation of the theoretical domains framework for use in behaviour change and implementation research. Implement Sci. 2012;7:37.

59. Davis R, Campbell R, Hildon Z, Hobbs L, Michie S. Theories of behaviour and behaviour change across the social and behavioural sciences: a scoping review. Health Psychol Rev. 2015;9(3):323-44.

60. Michie S, Richardson M, Johnston M, Abraham C, Francis J, Hardeman W, et al. The behavior change technique taxonomy ( $v 1)$ of 93 hierarchically clustered techniques: building an international consensus for the reporting of behavior change interventions. Ann Behav Med. 2013;46(1):81-95.

61. Aubel J. The role and influence of grandmothers on child nutrition: culturally designated advisors and caregivers. Matern Child Nutr. 2012;8(1): 19-35.

62. Bich TH, Hoa DT, Malqvist M. Fathers as supporters for improved exclusive breastfeeding in Viet Nam. Matern Child Health J. 2014;18(6):1444-53.

63. Biran A, Schmidt WP, Varadharajan KS, Rajaraman D, Kumar R, Greenland K, et al. Effect of a behaviour-change intervention on handwashing with soap in India (SuperAmma): a cluster-randomised trial. Lancet Glob Health. 2014; 2(3):e145-54.

64. Gautam OP, Schmidt WP, Cairncross S, Cavill S, Curtis V. Trial of a novel intervention to improve multiple food hygiene behaviors in Nepal. Am J Trop Med Hyg. 2017;96(6):1415-26.

65. White S, Schmidt W, Sahanggamu D, Fatmaningrum D, van Liere M, Curtis $\checkmark$. Can gossip change nutrition behaviour? Results of a mass media and community-based intervention trial in East Java, Indonesia. Trop Med Int Health. 2016:21(3):348-64.

66. Ellis A, McClintic E, Awino E, Freeman M. Designing an adapted behavioral trial for testing integrated interventions aimed at nutrition and WASH behavior change in Migori and Homa Ba, Kenya. Atlanta: Emory University Rollins School of Public Health; 2017.

67. Wolf J, Pruss-Ustun A, Cumming O, Bartram J, Bonjour S, Cairncross S, et al. Assessing the impact of drinking water and sanitation on diarrhoeal disease in low- and middle-income settings: systematic review and meta-regression. Trop Med Int Health. 2014;19(8):928-42.

68. Watson J, D'Mello-Guyett L, Flynn E, Falconer J, Esteves-Mills J, Prual A, et al. Interventions to improve water supply and quality, sanitation and handwashing facilities in healthcare facilities, and their effect on healthcareassociated infections in low-income and middle-income countries: a systematic review and supplementary scoping review. BMJ global health. 2019;4(4):e001632

69. Bhutta ZA, Das JK, Walker N, Rizvi A, Campbell H, Rudan I, et al. Interventions to address deaths from childhood pneumonia and diarrhoea equitably: what works and at what cost? Lancet. 2013;381(9875):1417-29.

70. Dewey KG, Adu-Afarwuah S. Systematic review of the efficacy and effectiveness of complementary feeding interventions in developing countries. Matern Child Nutr. 2008;4(Suppl 1):24-85.

71. Lassi ZS, Das JK, Zahid G, Imdad A, Bhutta ZA. Impact of education and provision of complementary feeding on growth and morbidity in children less than 2 years of age in developing countries: a systematic review. BMC Public Health. 2013;13(Suppl 3):S13.

72. Sinha B, Chowdhury R, Upadhyay RP, Taneja S, Martines J, Bahl R, et al. Integrated interventions delivered in health systems, home, and community 
have the highest impact on breastfeeding outcomes in low- and middleincome countries. J Nutr. 2017;147(11):2179S-87S.

73. Masset E, Haddad L, Cornelius A, Isaza-Castro J. Effectiveness of agricultural interventions that aim to improve nutritional status of children: systematic review. BMJ. 2012;344:d8222.

74. Aboud FE, Singla DR. Challenges to changing health behaviours in developing countries: a critical overview. Soc Sci Med. 2012;75(4):589-94.

75. Osendarp SJ, Roche ML. Behavioral change strategies for improving complementary feeding and breastfeeding. World Rev Nutr Diet. 2016;115: 184-92.

76. Girard AW, Olude O. Nutrition education and counselling provided during pregnancy: effects on maternal, neonatal and child health outcomes. Paediatr Perinat Epidemiol. 2012;26(Suppl 1):191-204.

77. Baker J, Sanghvi T, Hajeebhoy N, Abrha TH. Learning from the design and implementation of large-scale programs to improve infant and young child feeding. Food Nutr Bull. 2013;34(3 Suppl):S226-30.

78. Baker J, Sanghvi T, Hajeebhoy N, Martin L, Lapping K. Using an evidencebased approach to design large-scale programs to improve infant and young child feeding. Food Nutr Bull. 2013;34(3 Suppl):S146-55.

79. Sanghvi T, Jimerson A, Hajeebhoy N, Zewale M, Nguyen GH. Tailoring communication strategies to improve infant and young child feeding practices in different country settings. Food Nutr Bull. 2013;34(3 Suppl):S169-80.

80. Davis E, Cumming O, Aseyo RE, Muganda DN, Baker KK, Mumma J, et al. Oral Contact Events and caregiver hand hygiene: implications for fecal-oral exposure to enteric pathogens among infants 3-9 months living in informal, peri-urban communities in Kisumu, Kenya. Int J Environ Res Public Health. 2018;15:2.

81. Fabrizio CS, van Liere M, Pelto G. Identifying determinants of effective complementary feeding behaviour change interventions in developing countries. Matern Child Nutr. 2014;10(4):575-92.

82. Habicht J-P, Pelto GH, Lapp J. Methodologies to evaluate the impact of large scale nutrition programs (English). Washington, DC: World Bank; 2009.

83. Diep CS, Chen TA, Davies VF, Baranowski JC, Baranowski T. Influence of behavioral theory on fruit and vegetable intervention effectiveness among children: a meta-analysis. J Nutr Educ Behav. 2014:46(6):506-46.

84. National Institute for Health and Clinical Excellence. Behaviour change at population, community and individual levels. London; 2007.

85. Kirby DB, Laris BA, Rolleri LA. Sex and HIV education programs: their impact on sexual behaviors of young people throughout the world. J Adolesc Health. 2007;40(3):206-17.

86. Tate DF, Lytle LA, Sherwood NE, Haire-Joshu D, Matheson D, Moore SM, et al. Deconstructing interventions: approaches to studying behavior change techniques across obesity interventions. Transl Behav Med. 2016;6(2):236-43

87. Suntornsut P, Wongsuwan N, Malasit M, Kitphati R, Michie S, Peacock SJ, et al. Barriers and recommended interventions to prevent melioidosis in Northeast Thailand: a focus group study using the Behaviour Change Wheel. PLoS Negl Trop Dis. 2016;10(7):e0004823.

88. English M. Designing a theory-informed, contextually appropriate intervention strategy to improve delivery of paediatric services in Kenyan hospitals. Implement Sci. 2013;8:39.

89. Bresee S, Caruso BA, Sales J, Lupele J, Freeman MC. 'A child is also a teacher': exploring the potential for children as change agents in the context of a school-based WASH intervention in rural Eastern Zambia. Health Educ Res. 2016:31(4):521-34.

\section{Publisher's Note}

Springer Nature remains neutral with regard to jurisdictional claims in published maps and institutional affiliations.

Ready to submit your research? Choose BMC and benefit from:

- fast, convenient online submission

- thorough peer review by experienced researchers in your field

- rapid publication on acceptance

- support for research data, including large and complex data types

- gold Open Access which fosters wider collaboration and increased citations

- maximum visibility for your research: over $100 \mathrm{M}$ website views per year

At $\mathrm{BMC}$, research is always in progress.

Learn more biomedcentral.com/submissions 